\title{
How do admission systems affect enrolment in public tertiary education?
}

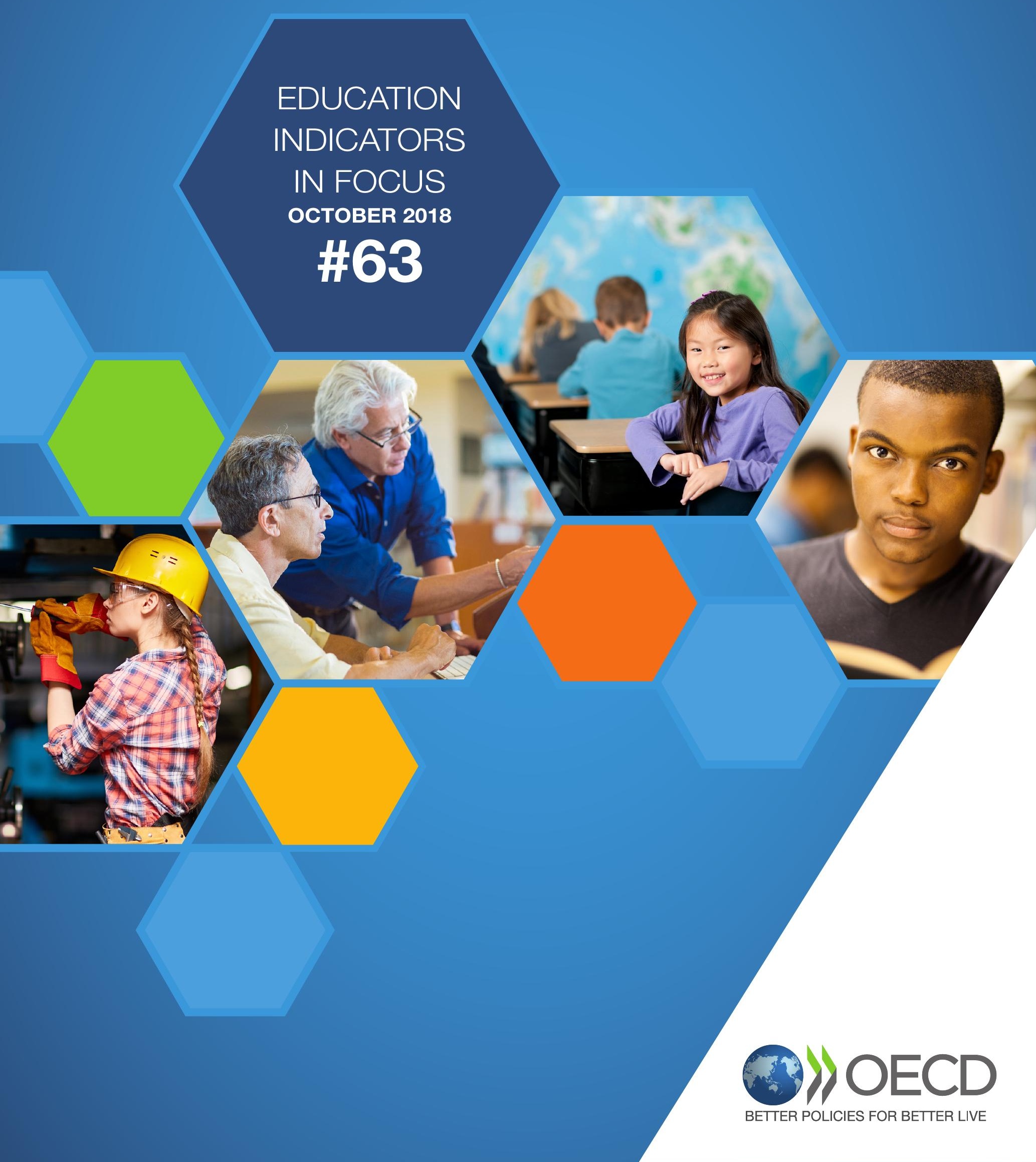




\section{How do admission systems affect enrolment in public tertiary education?}

- Based on a survey of 38 countries and economies, most have some form of selective admission to public tertiary education, at least in some fields or to some institutions.

- Centralised admission systems into public tertiary institutions are used in one-third of the countries and economies and may be used as a way to limit admissions.

- Performance assessment of applicants through national/central examinations taken towards the end of upper secondary education is used as a selection test for entry into at least some public institutions in half of the countries. Entrance examinations administered by tertiary institutions are also used in one-third of countries.

- Grade point averages, candidate interviews and work experience are among the other factors most often taken into account by selective admission systems, but most countries have measures to promote tertiary enrolment and equity in the application systems.

\section{Box 1. Sources}

This information on national criteria and admission systems for students applying for and entering first-degree tertiary programmes is based on the results of a survey administered in 2017 focusing on formal requirements. As practices can vary considerably between individual schools and tertiary institutions in each country, this survey cannot capture the diverse array of practices in the 38 participating countries and economies. For more details, see Indicator D6 of Education at a Glance 2017 (OECD, 2017 ${ }_{[1]}$ ).

Data on the number of applicants and applications to first-degree tertiary programmes refer to a survey administered in 2018. Among the 30 participating countries and economies, only 13 provided data on the number of applications and on the number of applicants by the result of their applications (accepted and studying, accepted but not studying, or rejected as they did not receive a positive answer to any of their applications) (OECD, 2018 ${ }_{[2]}$ ).

In recent decades, the educational attainment of the population has increased significantly in most countries and economies. The share of young adults (25-34 year-olds) without an upper secondary qualification declined from $20 \%$ in 2007 to 15\% in 2017 on average across OECD countries. In parallel, the proportion of adults with a tertiary qualification increased: from 34\% of 25-34 year-olds in 2007 to $44 \%$ in 2017.

This increase in the attainment level of the population results from the increase in the number of tertiary students. It is estimated that, on average across OECD countries, 57\% of young adults in 2016 (excluding international students) will enter tertiary education in their lifetime (based on first-time entrants), ranging from 15\% in Luxembourg to $71 \%$ in Chile. Several factors may contribute to these differences between countries, such as the potential number of people with an upper secondary qualification, the outcomes of tertiary education (in terms of employment and earnings) or the availability of tertiary programmes. Differences between countries may also relate to their admission systems to tertiary institutions.

The results of an OECD survey on national criteria and admission systems for students to apply for and enter firstdegree tertiary programmes (see Box 1) sheds some light on the way admission systems may affect enrolment in these programmes in public tertiary institutions.

\section{Most countries limit the number of student places in tertiary institutions to some extent}

The type of admission systems used may have a significant impact on enrolment. Whereas open admission or non-selective systems ensure that everyone with the required upper secondary qualification can enrol in a tertiary programme, some countries have selective systems to limit the number of available places in tertiary institutions. Open admission systems promote universal access while selective systems create competition between applicants to attract and retain the most skilled students. However, even countries with open admission systems may have some limitations or selection mechanisms, including for public institutions. The rationale for selectivity can vary significantly between countries. Some restrain access due to funding constraints at the tertiary level while others see selection as a way to filter for students more likely to successfully complete their studies. These selection mechanisms may raise equity issues, particularly in countries with unequal learning opportunities at lower levels of education.

Of the 35 countries that participated in the survey and had data available on public tertiary institutions, about half only have selective admissions systems, mostly related to limiting places by tertiary institutions). In the other half of countries with open admission systems, all except the Flemish and French communities of Belgium have some limitations or selection process, for at least some fields of study or some institutions. Limitations are mainly related to fields of study, with only Canada, Colombia, France, the Slovak Republic and the United States having a selective process to enter at least some tertiary institutions. Countries with selective systems more often limit enrolment by tertiary institutions than by field of study (Figure 1). In Estonia, Finland and Norway, the limited number of student places in tertiary institutions may delay entry into tertiary education and goes some way towards explaining why new entrants into tertiary education are on average one year older than the OECD average (23 years old compared to 22). 
FIGURE 1 / Use of limits on number of students entering fields of education and institutions within countries with open and selective systems in public tertiary institutions (2017)

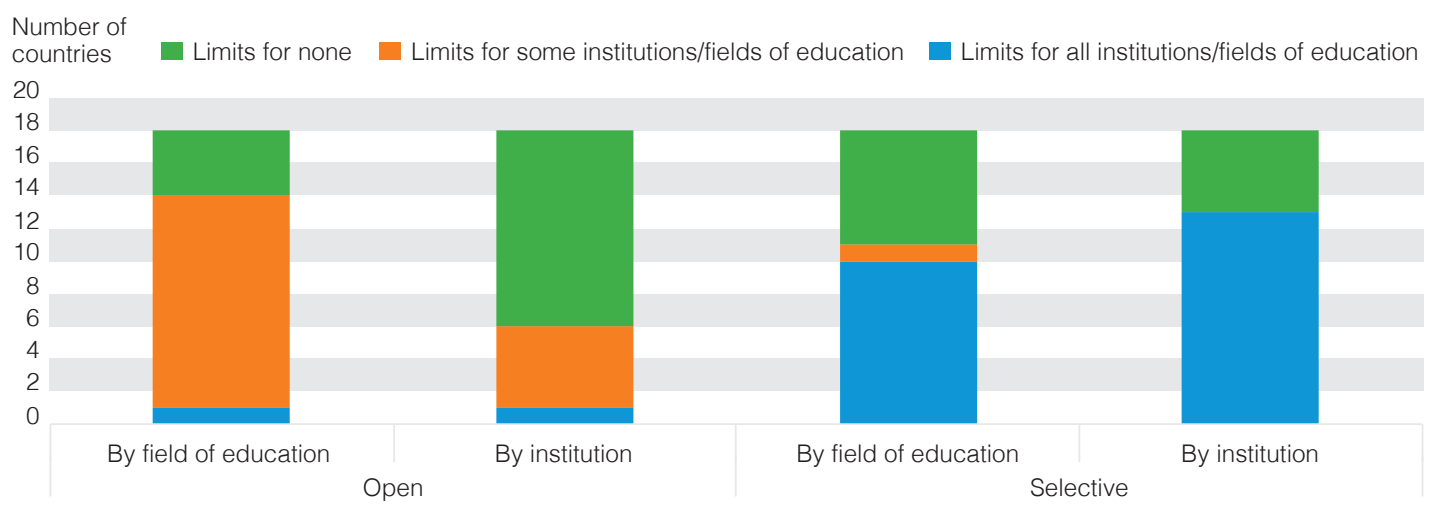

Public institutions

How to read this figure: First-degree tertiary programmes within countries with open admissions systems can still be subject to limitations on the number of places available, either by field of education or institution. These limits may affect all fields of education or types of institutions, only some, or none at all. Similarly, for countries with selective systems, limits may be set with reference to field of study and/or institutions. As such, a country with a selective system may still report no limits (none) for one of these dimensions.

Note: Of the 38 countries that participated in the survey, this figure does not include those for which the information is missing or not applicable.

Source:

OECD (2017), Table D6.1. See Source section for more information and Annex 3 for notes (www.oecd.org/education/ education-at-a-glance-19991487.htm).

Limitations on the number of available places for students may reflect the capacities of institutions (in terms of the number of teachers or infrastructure) to enrol students. For example, in Denmark, the type of admission system is determined by the number of applicants. There is open admission when there are fewer applicants than the number of study places, but some selection is introduced when the number of applicants exceeds the number of study places. Limitations on places can also result from the authorities' decision to limit the number of students graduating from a specific field of study. These decisions are related to labour market opportunities or as a result of an assessment by the government of the needs for the population. This is often the case for fields of study with high employment prospects, such as those ones related to health. For example, in Italy, each year the Ministry of Education defines the number of student places available nationally in medicine, dentistry and other health professions, in addition to in veterinary medicine and architecture.

\section{Most countries with a centralised admission process limit the number of applications students can make}

Centralised admission systems, which require tertiary applicants to use a single system to apply to different programmes and institutions, may give students the advantage of only preparing one application to access a large number of different tertiary programmes. They can also be a tool to manage access to tertiary education and avoid multiple enrolments of students. Nearly one-third of the countries and economies with data used a centralised admission process for public tertiary institutions and a similar share combine centralised systems (for some tertiary programmes) with direct applications to other tertiary institutions. For example, in Hungary students apply through a centralised system for all programmes except religious programmes for which they apply directly to the higher education institutions.

With centralised systems, some countries limit the number of applications or preferences that each student can submit, or limit the number of offers made to students. While there are no limitations in Greece, Italy and New Zealand, the maximum number of applications ranges from 2 in Brazil to 24 in Turkey and France in 2015. In Chile, Denmark, Finland, France, Germany, Greece, Lithuania, Portugal, Slovenia, Sweden and Turkey, students can submit several applications, but will receive only one offer.

\section{Combining more selection criteria increases the selectivity}

In all countries, an upper secondary qualification is required to access public tertiary education. However this is not necessarily a sufficient requirement, even in countries with some open admission systems.

In about half of the countries and economies which participated in the survey, upper secondary graduates also have to meet a minimum academic performance (set by the government) in order to enter at least some first-degree tertiary programmes or institutions (public or private). These minimum requirements are more often set for specific fields of study rather than specific tertiary institutions: 13 countries set requirements for some fields, while 8 set requirements for some or all tertiary institutions. Various performance assessments could be used for this purpose (OECD, 2017 $[1]$ ).

Examinations or tests administered to upper secondary students (either national/central or non-national/central examinations that may be either standardised or non-standardised tests, see definitions) are a widespread criterion for admission to tertiary education. About two-thirds of countries and economies that submitted data have a national or central examination at the end of upper secondary education. In nearly all of them, more than three-quarters of upper secondary students take these tests, which are compulsory to gain access to most public tertiary institutions.

The recognition of a single common examination by all tertiary institutions eases the admission process, reduces the required funding by governments and public institutions, favours equity, and increases the number of institutions 
students can apply to (compared to systems where one application is necessary for each tertiary institution). However, in some countries tertiary institutions may also establish their own tests to select students. These tests are used in 20 countries, but only by public institutions in 12 of them.

FIGURE 2 / Factors other than performance assessment used for admission in first-degree tertiary programme in public institutions (2017)

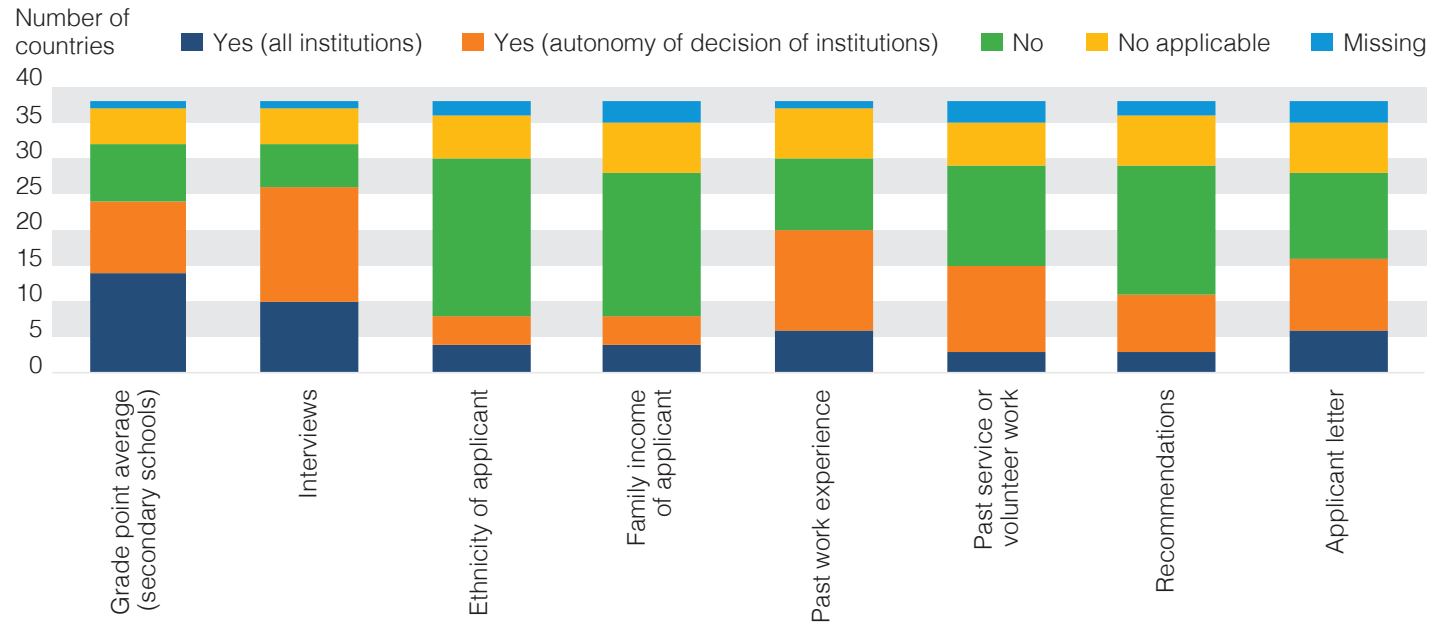

Source: OECD (2017), Table D6.8. See Source section for more information and Annex 3 for notes (www.oecd.org/education/education-at-aglance-19991487.htm).

As Figure 2 shows, public institutions use other factors besides performance assessment to determine access to firstdegree tertiary programmes. Other than upper secondary grade point averages, the most frequently used criteria in deciding to accept a student are: interviews (used in 26 countries), past work experience (in 20 countries), past service or voluntary work (in 15 countries), candidate recommendations (in 11 countries) and written application letters (in 16 countries). These can be used in isolation or in combination with several factors. For example, Hungary only uses students' grade point average from secondary school, in addition to their successful completion of national examinations, to determine access to public tertiary institutions (OECD, 2017 ${ }_{[1]}$ ).

Countries with the highest proportions of rejected applicants to tertiary education - those who did not receive a positive result from any of their applications - reveal highly selective admission systems,. Among 13 countries with available data (see Box 1), the proportion of rejected applicants varies from less than $5 \%$ in Australia to more than $60 \%$ in Finland and Sweden (Figure 3). In these last two countries, admissions are restricted for all programmes and fields of study, and the number of admissions results from a negotiation between tertiary institutions and the central government. These national rates may conceal larger variations within countries between different fields of study. In contrast, France has low selectivity for entry into tertiary education, and applicants can make a large number of applications through a centralised system, with nearly $90 \%$ of applicants accepted into and studying in one of the programmes they applied for. However, this low selectivity might mean that some of the accepted students do not have the skills or knowledge they will need to successfully graduate from tertiary education.

\section{Some admission systems differ for international students}

About half of the countries and economies surveyed implemented a different admission process for international students although in one-quarter of them this different process only applies to applicants from some countries. For example there is no difference in the process for students from countries of the European Union (EU) applying to study in another EU country. All these countries with a different admission process for international students require (at least) accredited school certificates from students' home countries and language proficiency. These criteria are also requested in at least two-thirds of the countries where application systems are similar for non-national/international and national students. These criteria may provide information on the ability of international students to successfully complete the programmes they are applying for.

Enrolment of international students may be also limited by the levels of tuition fees. In 11 of the 38 countries which participated in the survey, tuitions fees are significantly higher for international students than for national ones more than three times as much in Australia and Canada and about twice as much in Austria and the United States. In spite of higher fees, however, the number of international students keeps increasing every year, particularly in English-speaking countries.

\section{Admission mechanisms can be adjusted to promote enrolment or ensure equity}

Most governments have also implemented measures to favour socio-economic and gender equity in access to tertiary education, or more generally to create incentives for people to apply to tertiary programmes (Figure 4). Apart from the Czech Republic and Iceland, which reported no such measures, countries reported using measures related to tuition fees or financial support for students or more generally measures to boost enrolment among targeted population groups or towards specific fields of study. 
FIGURE 3 / Applicants to first-degree tertiary education by application status (2016).

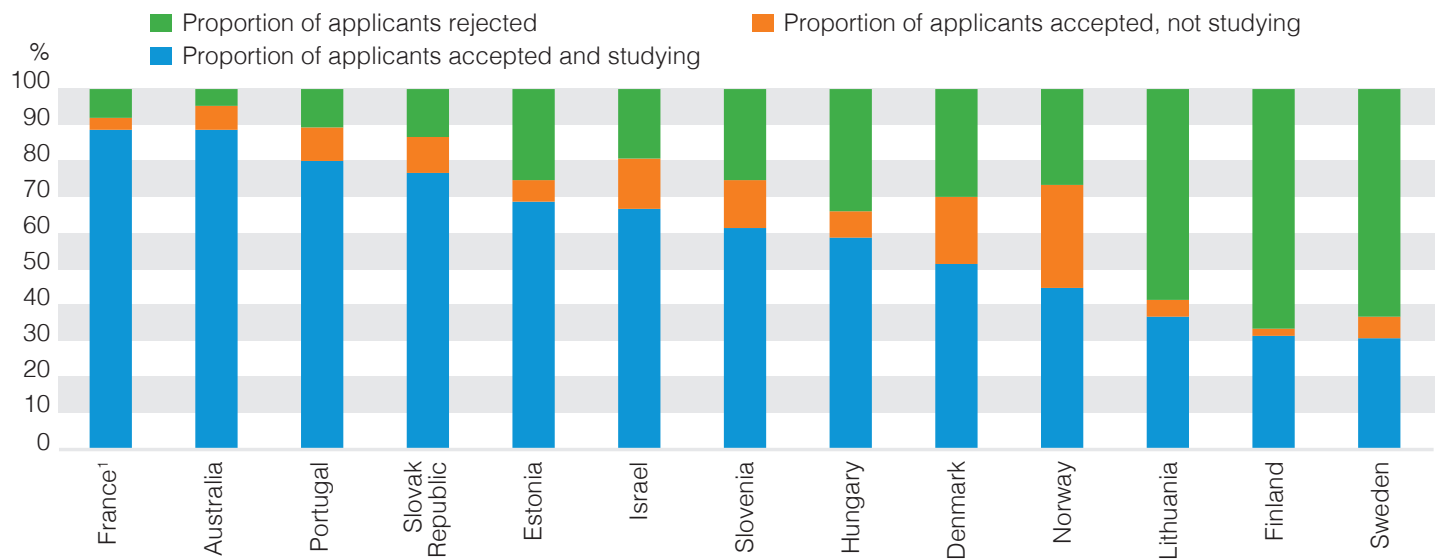

1. Including applicants to short-cycle tertiary programmes.

Countries are ranked in descending order of the proportion of applicants accepted and studying.

Source: OECD (2018). See Annex 3 for notes (www.oecd.org/education/education-at-a-glance-19991487.htm).

Tuition fees and other costs faced by students may create financial barriers to entering tertiary education, especially for students from lower socio-economic backgrounds. Reducing these costs may promote more equal access to tertiary education. In 12 out of the 38 countries and economies surveyed, students do not have to pay any tuition fees for first-degree tertiary programmes, and in 4 countries students are only required to pay administrative fees. Other government measures to reduce tuition costs include subsidised fees (contribution fees), a cap on the amount of fees or lower fees for specific fields. A large number of countries also provide financial support to students. Tax allowances/reductions/credits, scholarships or other grants to households and student loans are the most common type of support, and are available in at least half of the countries with available information. Among the remaining countries, about $85 \%$ of them provide financial support to students through public loans or scholarships. For example, since 2016 Chile has implemented a no tuition fees benefit (Gratuidad) as part of the current government's educational reform. However, this is not a universal benefit - it finances $50 \%$ of the most vulnerable students who meet certain academic requirements. Measures like these to lower the financial cost of tertiary studies may contribute (alongside other factors such as the financial return from a tertiary education) to explaining the high entry rates in countries such as Australia, Chile and New Zealand in spite of higher tuition fees.

\section{FIGURE 4 / Policies, measures and campaigns implemented by the government to support/increase} participation in first-degree tertiary programmes (2017)

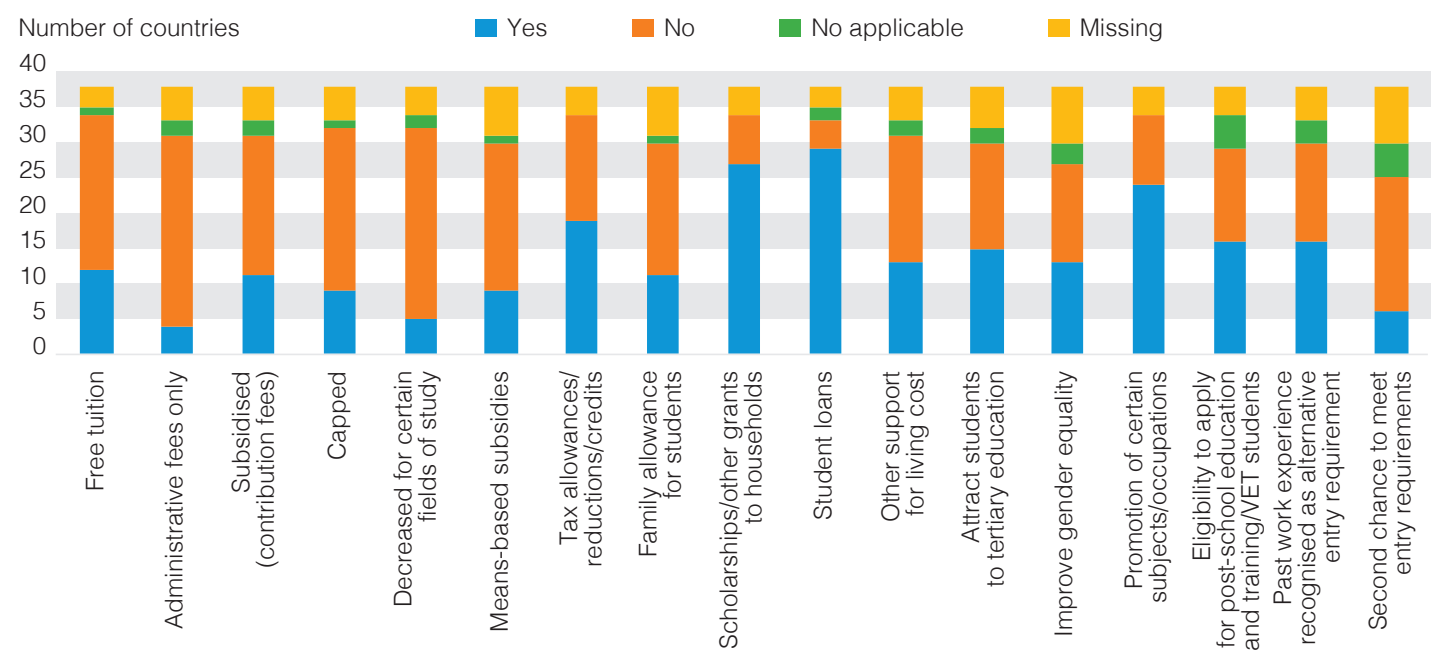

Source: OECD (2017), Table D6.2 available on line. See Source section for more information and Annex 3 for notes (www.oecd.org/education/ education-at-a-glance-19991487.htm).

Half of the countries with available information also implemented measures to promote gender equality in tertiary education. In 2016, on average among OECD countries, only 1\% of women graduating had studied information and communication technologies and 6\% engineering, manufacturing and construction, while for men the figures were $7 \%$ and $25 \%$ respectively. Therefore, some countries have tried to foster women's enrolment rates in some fields of study. For example, Italy developed the initiative "STEM Month - Women want to count", aiming at triggering debate on the subject, encouraging students to undertake science, technology, engineering and mathematics (STEM) subjects, and combating gender stereotypes and discrimination in schools, with the support of associations and other stakeholders (61st Session of the Commission of the Status of Women, $2017_{[3]}$ ). 


\section{The bottom line}

Both the admission process and criteria for admission affect tertiary enrolment. Centralised admission systems can make the admission process more efficient, but can limit the number of applications and offers made to applicants; minimum performance requirements or tuition fees are barriers to tertiary studies, even if adjustments are made for specific groups or for equity reasons. This snapshot of tertiary education admission systems enables a better analysis of the implications of these different policies across different settings and so helping provide a clearer understanding of what matters for outcomes.

\section{Definitions}

A standardised examination or test refers to a test that is administered and scored under uniform conditions across different schools so that student scores are directly comparable between schools.

National/central examinations are standardised tests that have a formal consequence for students, such as their eligibility to progress to a higher level of education or to complete an officially recognised degree. They assess a major portion of what students are expected to know or be able to do in a given subject.

Other (non-national/central) standardised examinations are standardised tests that are administered and scored under uniform conditions across different schools at the state/territorial/provincial/regional or local level so that student scores are directly comparable.

Entrance examinations are examinations not administered by upper secondary schools that are typically used to determine, or help to determine, access to tertiary programmes. These examinations can be devised and/or graded at the school level (i.e. by individual tertiary institutions or a consortium of tertiary institutions), or by private companies.

\section{FOR MORE INFORMATION:}

$61^{\text {st }}$ Session of the Commission of the Status of Women (2017), Promoting STEM as an essential factor for women's labor inclusion and career advancement, http://esango.un.org/SideEvents/ documents/2013.

OECD (2018), Education at a Glance 2018: OECD Indicators, OECD Publishing, Paris, http://dx.doi.org/10.1787/ eag-2018-en.

OECD (2017), Education at a Glance 2017: OECD Indicators, OECD Publishing, Paris, http://dx.doi.org/10.1787/ eag-2017-en.

VISIT

www.oecd.org/education/education-at-a-glance-19991487.htm

Education Indicators in Focus (previous issues)

PISA in Focus

Teaching in Focus

NEXT TOPIC Where do inequities in education start appearing?

Photo credit: () Christopher Futcher / iStock; @ Marc Romanelli / Gettyimages; @ michaeljung / Shutterstock; @ Pressmaster / Shutterstock This work is published under the responsibility of the Secretary-General of the OECD. The opinions expressed and arguments employed herein do not necessarily reflect the official views of OECD member countries.

This document, as well as any data and any map included herein, are without prejudice to the status of or sovereignty over any territory, to the delimitation of international frontiers and boundaries and to the name of any territory, city or area.

The statistical data for Israel are supplied by and are under the responsibility of the relevant Israeli authorities. The use of such data by the OECD is without prejudice to the status of the Golan Heights, East Jerusalem and Israeli settlements in the West Bank under the terms of international law. 